\section{Mechano-Chemical Anodic Dissolution}

Hoar and Hines ${ }^{1-5}$ have studied the transgranular stress-corrosion cracking of 18-8 type stainless steels in aerated aqueous magnesium chloride solution (42 wt.-per cent of magnesium chloride) at temperatures of $120-154^{\circ} \mathrm{C}$., using thin wires directly stressed in tension. They found rates of crack propagation in the range $0.5-2 \mathrm{~mm}$./hr., similar to those found in other work using much thicker material, and several orders of magnitude smaller than the rate of cracking in mechanical brittle fracture. They suggested that a crack is propagated by the selective anodic dissolution of the highly stressed metal forming its advancing edge, the unstressed sides of the crack remaining relatively unattacked.

By measurements of the electrode potential of cracking wires, and of potential and current density on unstressed wires polarized cathodically with impressed e.m.f., they estimated the current flowing from the surface oxide-film cathode into each crack as of the order of $0.5 \mu \mathrm{mmp}$; this, together with the anodic current-density at the advancing edge necessary to give the observed rate of crack propagation by metal dissolution to $\mathrm{Fe}_{\Theta} \mathrm{II}, \mathrm{Cr} I \mathrm{II}$ and $\mathrm{NiII}$, say $0 \cdot 4$ $1.6 \mathrm{~A} . / \mathrm{cm} .^{2}$, leads to reasonable values of the width of the advancing edge, some tens or hundreds of angstroms. The potential measurements also showed that the postulated anodic dissolution of stressed metal at high current density must take place, if it in fact occurs, with only a few millivolts polarization of the anode above its zero-current potential of about $-0.15 \mathrm{~V}$. ( $N$-hydrogen scale $)$. While there are no grounds for supposing that stressed or even strained metal is, per se, much more easily dissolved anodically than unstressed metal, it seemed possible that metal in the act of yielding under stress might be so. Measurements of the overall extension of wires during cracking suggested that the actual strain-rate at the advancing edge of each crack may well be of the order of 10-100 per cent/sec., and it was thus of interest to see whether a macroseopic area of 18-8 type stainless steel yielding at a comparable rate could sustain a high anodic current density of the order of $1 \mathrm{amp} . / \mathrm{cm} .{ }^{2}$, leading to equivalent metal dissolution, at very small polarization.

We have modified the apparatus of Hoar and Hines $^{1-5}$ so that in it a wire may be extended very rapidly while it undergoes anodic polarization in a hot aqueous solution. Arrangements for the simultaneous measurement of extension-rate, electrode potential and current are included, and for the rapid flow of the solution past the wire if required.

When an unstressed wire of 18-8 steel (carbon, 0.09 ; silicon, 1.00 ; manganese, 0.78 : chromium, $17 \cdot 1$; nickel, 9.2 ; molybdenum, 0.18 ; copper, 0.2 ; nitrogen, 0.06 ; niobium + tantalum, titanium, $<0.05$ wt.-per cent) was polarized anodically in stagnant 42 wt.-per cent aqueous magnesium chloride solution at $154^{\circ} \mathrm{C}$. so that the current density was $0.5 \mathrm{mmp} . / \mathrm{cm} .{ }^{2}$, the potential was $+0.52 \mathrm{~V}$. and the wire dissolved uniformly over its whole surface to $\mathrm{Fe}^{\mathrm{II}}, \mathrm{Cr} \mathrm{III}$ and $\mathrm{Ni}$ II with about 100 per cent current efficiency. When a similar wire was treated similarly during its extension at 5 per cent/sec., the potential was $+0.35 \mathrm{~V}$. and similar uniform dissolution occurred. The rapid macroscopic dissolution produced, however, considerable concentration polarization caused by the accumulation of dissolved metrl ions in the liquid adjacent to the wire. To reduce this, further experiments, in which similar wires were extended at 5 per cent/sec. while dissolving at $0.5 \mathrm{amp} . / \mathrm{cm} .{ }^{2}$, were made with the solution forced at $50 \mathrm{~cm}$. $/ \mathrm{sec}$. past the wire (which was held in the axis of a 1-cm.-diam. glass tube) : the potential was now $-0.15 \mathrm{~V}$., very close to the zero-current potential of unstressed 18-8 steel anodes and slightly more negative than the potentials observed during stresscorrosion cracking ${ }^{1-5}$, the wire again dissolving uniformly.

These experiments demonstrate that 18-8 steels can dissolve anodically at high current density with very small polarization provided that the surface is yielding rapidly in a direction normal to the direction of dissolution. They provide strong confirmation for the hypothesis of Hoar and Hines for the mechanism of crack propagation; as we shall show in a full report of this work elsewhere, concentration polarization at a very small anode at the advancing edge of a yawning crack is likely to be very small. The experiments also provide an example, on the macroscopic scale, of a mechano-chemical effect: an anodic dissolution that is highly stimulated by the mechanically induced movement of the surface metal atoms.

Similar experiments on pure nickel gave no indication of mechanical stimulation of its anodic dissolution in hot aqueous magnesium chloride solution; significantly, nickel does not suffer stress-corrosion cracking under these conditions. Although 18-8 steel and nickel both have face-centred cubic lattices, the number, distribution and mobility of dislocations and other zones of disarray are clearly different in the alloy and in the pure metal, which may well account for the difference in their behaviour when they undergo simultaneous yielding and dissolution.

\section{T. P. HOAR}

J. M. WEST

Department of Metallurgy,

University of Cambridge. Jan. 29.

${ }^{1}$ Hoar, T. P., and Hines, J. G., J. Iron and Steel Inst., 182, 124 (1956). ${ }^{2}$ Hines, J. G., and Hoar, T. P., J. Iron and Steel Inst., 184, 166 (1956).

${ }^{3}$ Hoar, T. P., and Fines, J. G., Symposium on Stress Corrosion Hoar, T. P., and Fines, J. G., Symposium on Str.
Cracking and Emorittlement, 107 (Wiley, 1956).

4 Hoar, T. P., and Hines, J. G., International Committee for Electrochemical Thermodynamics and Kinetics (CITCE), 8th Meeting (Butterworths, London) (in the press).

${ }^{5}$ Hines, J. G., and Hoar, T. P., J. App. Chem. (in the press).

\section{Electronic Configuration of Cations in some Distorted Spinels}

Two apparently different approaches have been used for explaining the distortion to tetragonal symmetry of some spinels. Both, however, rely on the behaviour of cations having $3 d$ electrons. Thus in one the origin of distortion is attributed to the ability of these cations (for example, $\mathrm{Mn}^{3}+$ ) to form the appropriate covalent bonds with the overlapping oxygen orbitals ${ }^{1-3}$. On the other hand, the second approach relates it to the crystal field effects and Jahn-Teller distortions ${ }^{4}$ of ligands around such cations $^{5}$.

In what follows the observed electronic configuration of cations in a few cases is examined in the light of these schemes. The analysis of the available magnetic data for $\mathbf{M n}^{2}+\left[\mathrm{Mn}_{2}^{3+}\right] \mathrm{O}_{4}^{2}-$ and for the $\gamma$-oxide $\left(\mathbf{M n}_{2}^{8}+\mathrm{O}_{3}^{2-}\right)$ showed that $\mathbf{M n}^{3+}\left(d^{4}\right)$ ions at octahedral sites in both the substances have four unpaired $d$-electrons. However, the tetrahedrally situated cations, that is $\mathrm{Mn}^{2}+\left(d^{5}\right)$ in the former and 